\section{Venetoclax plus bendamustine-rituximab or bendamustine-obinutuzumab in chronic lymphocytic leukemia: final results of a phase lb study (G028440)}

\author{
Stephan Stilgenbauer, ${ }^{1}$ Franck Morschhauser, ${ }^{2}$ Clemens-Martin Wendtner, \\ Guillaume Cartron, ${ }^{4}$ Michael Hallek, ${ }^{5}$ Barbara Eichhorst, ${ }^{5}$ Mark F. Kozloff, ${ }^{6}$ \\ Thomas Giever, ${ }^{7}$ Gerard Lozanski, ${ }^{8}$ Yanwen Jiang, ${ }^{9}$ Huang Huang, ${ }^{10}$ \\ Daniela Soriano Pignataro, ${ }^{11}$ William Schary, ${ }^{12}$ Kathryn Humphrey, ${ }^{11}$ \\ Mehrdad Mobasher ${ }^{9}$ and Gilles Salles ${ }^{13^{\circ}}$
}

Volume 106(11):2834-2844

\begin{abstract}
${ }^{1}$ Department of Internal Medicine III, UIm University, Ulm, Germany; ${ }^{2}$ University of Lille, Groupe de Recherche sur les Formes Injectables et les Technologies Associées, Lille, France; ${ }^{3}$ Munich Clinic Schwabing, Academic Teaching Hospital, Ludwig-MaximiliansUniversity (LMU), Munich, Germany; ${ }^{4}$ Department of Clinical Hematology, University Hospital of Montpellier, Montpellier, France; ${ }^{5}$ Department I of Internal Medicine, Center of Integrated Oncology Cologne-Bonn, University Hospital Cologne, Cologne, Germany; ${ }^{6}$ Duchossois Center for Advanced Medicine, University of Chicago Medicine, Chicago, IL, USA; ${ }^{7}$ Department of Medicine, Medical College of Wisconsin, Milwaukee, WI, USA; ${ }^{8}$ Department of Pathology, The Ohio State University, Columbus, OH, USA; ${ }^{9}$ Genentech, Inc., South San Francisco, CA, USA; ${ }^{10} \mathrm{~F}$. Hoffmann-La Roche Ltd, Mississauga, Ontario, Canada; ${ }^{11}$ Roche Products Ltd, Welwyn Garden City, UK; ${ }^{12}$ AbbVie Inc, North Chicago, IL, USA and ${ }^{13}$ Hospices Civils de Lyon, Université de Lyon, Pierre-Bénite, France
\end{abstract}

${ }^{\circ}$ Current address: Memorial Sloan Kettering Cancer Center, New York, NY, USA.

\section{ABSTRACT}

$\mathrm{V}$ enetoclax (Ven), an orally administered, potent BCL-2 inhibitor, has demonstrated efficacy in chronic lymphocytic leukemia (CLL) in combination with rituximab (R) or obinutuzumab $(\mathrm{G})$. Our aim was to investigate the addition of bendamustine (B) to these Ven-containing regimens in relapsed/refractory (R/R) or first-line (1L) CLL. This multi-arm, nonrandomized, open-label, phase $\mathrm{Ib}$ study was designed to evaluate the maximum tolerated dose (MTD) and safety/tolerability of Ven with BR/BG, with $3+3$ dose-escalation followed by safety expansion. Patients received Ven (schedule A) or BR/BG first (schedule B) to compare safety and determine dose/schedule for expansion. Six Ven-BR/-BG cycles were to be administered, then Ven monotherapy until disease progression (R/R) or fixed-duration 1year treatment (1L). Overall, $33 \mathrm{R} / \mathrm{R}$ and $501 \mathrm{~L}$ patients were enrolled. No dose-limiting toxicities were observed (doses 100-400 mg), and the MTD was not reached. Safety was similar between schedules; no tumor lysis syndrome occurred during dose-finding. Schedule B and Ven $400 \mathrm{mg}$ were chosen for expansion. The most frequent grade 3-4 toxicity was neutropenia: R/R $64 \%$, 1L Ven-BR 85\%, 1L Ven-BG 55\%. Grade 3-4 infection rate was: R/R 27\%, 1L Ven-BR 0\%, 1L Ven-BG 27\%. During expansion, one clinical and two laboratory tumor lysis syndrome cases occurred. Fewer than half the patients completed six combination therapy cycles with all study drugs; rates of bendamustine discontinuation were high. Overall response rate was $91 \%$ in $\mathrm{R} / \mathrm{R}$ and $100 \%$ in $1 \mathrm{~L}$ patients (16 of $491 \mathrm{~L}$ patients received Ven for $>1$ year). In conclusion, addition of bendamustine to Ven-R/-G increased toxicity without apparent efficacy benefit (clinicaltrial gov. Identifier: NCT01671904).

\section{Introduction}

Treatment of chronic lymphocytic leukemia (CLL) has evolved in recent years, resulting in improved survival, ${ }^{1}$ with chemo-immunotherapy being the standardof-care over the past decade. ${ }^{2}$ However, agents targeting pathways involved in CLL cell proliferation and survival, such as B-cell receptor signaling ${ }^{3,4}$ and B-cell lymphoma-2 (BCL-2), ${ }^{5}$ are now standard treatment options. ${ }^{6-14}$

Combination of the selective selective BCL-2 inhibitor venetoclax (Ven) with 
type II anti-CD20 antibody obinutuzumab (G; GA101) in a single-arm, phase Ib trial conferred high response rates with deep remission among patients with previously untreated (1L) or relapsed/refractory (R/R) CLL. ${ }^{13}$ Recently, Ven with rituximab (R) or $G$ demonstrated impressive efficacy in phase III CLL trials, ${ }^{6-8}$ leading to approval of Ven-R and Ven-G in the R/R and $1 \mathrm{~L}$ treatment settings, respectively. ${ }^{15,16}$ Bendabustine is an established chemotherapy agent in CLL that has shown clinical activity in combination with anti-CD20 antibodies. ${ }^{17-20}$ Whether the addition of a chemotherapy agent such as bendamustine to Ven-R or Ven-G could further improve outcomes in CLL has not yet been elucidated. The combination of Ven with bendamustine plus $\mathrm{R}$ (BR) produced greater growth inhibition in non-Hodgkin lymphoma (NHL) xenograft models than either Ven-R or BR alone, ${ }^{21}$ suggesting potential for increased clinical activity in B-cell malignancies. In addition, BCL-2 overexpression may be involved in resistance to the pro-apoptotic effects of chemoimmunotherapy, so the addition of Ven could overcome this and act as a chemosensitizer. ${ }^{22}$ We therefore evaluated a triplet combination of Ven with bendamustine and an anti-CD20 antibody (R or G) in $1 \mathrm{~L}$ and R/R CLL.

\section{Methods}

\section{Study design and treatment}

This phase Ib, multi-arm, non-randomized, open-label study (clinicaltrials gov. Identifier: NCT01671904) was conducted at 11 sites across USA and Europe. Review boards at all institutions approved the protocol. Patients provided written informed consent.

The study comprised two phases: dose-finding and safetyexpansion. Dose-finding, employing standard 3+3 dose escalation (Online Supplementary Table S1), was designed to include Ven doses from 100-600 mg daily with standard dose BR/BG (Figure 1; bendamustine: $90 \mathrm{mg} / \mathrm{m}^{2}$ (1L) or $70 \mathrm{mg} / \mathrm{m}^{2}$ (R/R) days (D) $1-2$ cycle (C)1-6; R: $375 \mathrm{mg} / \mathrm{m}^{2} \mathrm{D} 1 \mathrm{C} 1$ then $500 \mathrm{mg} / \mathrm{m}^{2} \mathrm{D} 1 \mathrm{C} 2-6$; G: $100 \mathrm{mg}$ D1, $900 \mathrm{mg} \mathrm{D2}, 1000 \mathrm{mg}$ D8 and D15 C1 then 1,000 mg D1 C26). In order to mitigate tumor lysis syndrome (TLS) risk, Ven was initiated using a weekly ramp-up to target dose (Figure 1). TLS prophylaxis included hydration, a uric acid reducer, and hospitalization (Online Supplementary Table S2).

Dose-finding compared two administration schedules for TLS risk mitigation during cycle 1 (Figure 1): schedule $\mathrm{A}$ (Ven ramp-up, followed by BR/BG) and schedule B (Ven introduced after 21-day $\mathrm{BR} / \mathrm{BG}$ loading period). After each stage, an internal monitoring committee (IMC) and scientific overview committee (SOC) reviewed the data and provided dose/schedule recommendations for subsequent dose-finding stages and safety expansion (Online Supplementary Figure S1).

Patients received six 28-day cycles of Ven-BR/-BG. R/R patients continued single-agent Ven until disease progression (PD), death, or unacceptable toxicity; $1 \mathrm{~L}$ patients received 6 months of singleagent Ven for a total of 1-year treatment duration. Ven could be extended in $1 \mathrm{~L}$ patients with detectable minimal residual disease $(\mathrm{MRD})$ in bone marrow (BM) and/or partial response after 1 year of treatment. See the Online Supplementary Appendix for further details of study treatments and procedures.

\section{Objectives}

Primary objectives were to identify the maximum tolerated dose (MTD) of Ven combined with BR, and evaluate safety/tolerability of Ven-BR in R/R and 1L CLL. Secondary objectives included efficacy evaluation of Ven-BR (including complete response
[CR], overall response rate [ORR], duration of response, and progression-free survival [PFS]). Exploratory objectives were to determine the MTD of Ven with BG, safety and efficacy of Ven-BG, and the undetectable MRD (uMRD) rate with Ven-BR/-BG.

\section{Patients}

Patients $\geq 18$ years with a diagnosis of CLL according to the International Workshop on CLL (iwCLL) 2008 guidelines, ${ }^{23}$ in need of therapy, with an Eastern Cooperative Oncology Group (ECOG) performance status of $0-1$ and adequate hematologic function (platelet count $\geq 75,000 / \mathrm{mm}^{3}$ or $\geq 30,000 / \mathrm{mm}^{3}$ if due to marrow involvement of CLL, and/or disease related immune thrombocytopenia; absolute neutrophil count $\geq 1,000 / \mathrm{mm}^{3}$; hemoglobin $\geq 9 \mathrm{~g} / \mathrm{dL}$ ) were eligible (Online Supplementary Table S3). Patients with R/R CLL must have received one to three prior lines of therapy.

\section{Assessments}

Baseline molecular characteristics were assessed centrally (Online Supplementary Appendix). Safety and tolerability were assessed by incidence and type of dose-limiting toxicities (DLT) (Online Supplementary Table S4), AE (graded according to National Cancer Institute Common Terminology Criteria for Adverse Events $v 4.0^{24}$ ), and serious $\mathrm{AE}$, laboratory variables, and vital signs. TLS was classified according to Howard criteria. ${ }^{25}$ Efficacy was assessed by investigators according to iwCLL 2008 guidelines. ${ }^{23}$

Central MRD assessment was performed at Ohio State University, USA using five-colour flow cytometry according to the European Research Initiative on CLL principle. ${ }^{26}$

\section{Statistical analyses}

Safety and efficacy analyses included all patients receiving $\geq 1$ dose of any study drug. Peripheral blood (PB) MRD analyses reported landmark $\mathrm{MRD}$ rates after treatment completion in the $1 \mathrm{~L}$ population and after antibody completion in the $\mathrm{R} / \mathrm{R}$ population, given the difference in duration of treatment in these two populations. MRD analysis populations included all patients reaching the specified landmark time-point, plus those discontinuing the study earlier for $\mathrm{AE}, \mathrm{PD}$, or death. Given the long recruitment time, some patients had not reached the specific timepoint, therefore the intention-to-treat approach was not used. At each landmark assessment, the first evaluable PB MRD sample after the specified time-point was used. For BM MRD, due to limited sampling, best MRD response was reported, calculated in the efficacy population. Time-to-event analyses employed Kaplan-Meier methodology. ${ }^{27}$

\section{Results}

\section{Patients}

Thirty-three R/R and $501 \mathrm{~L}$ patients were enrolled between January 2014 and June 2017 (Online Supplementary Figure S2). All R/R patients were enrolled in Ven-BR cohorts; 1L patients were enrolled in Ven-BR $(n=27)$ or Ven-BG $(n=23)$ cohorts. All $33 \mathrm{R} / \mathrm{R}$ patients were included in safety and efficacy analyses. One $1 \mathrm{~L}$ patient enrolled in the Ven-BG cohort did not receive study drug, therefore 49 patients (27 Ven-BR, 22 Ven-BG) were included in analyses. Data cutoff was 17 August 2018; no further follow-up will be available.

In $\mathrm{R} / \mathrm{R}$ patients, median number of prior CLL therapies was 1 (range, 1-3); 79\% had received fludarabine-based combinations and 6\% Bruton's tyrosine kinase inhibitors; none had received phosphoinositide-3-kinase inhibitors 
Table 1. Baseline characteristics.

\begin{tabular}{|c|c|c|c|}
\hline Characteristic & $\begin{array}{c}\mathrm{R} / \mathrm{R} \\
\mathrm{Ven}-\mathrm{BR} \\
(\mathrm{n}=33)^{*}\end{array}$ & $\begin{array}{c}1 L \\
\text { Ven-BR } \\
(n=27)\end{array}$ & $\begin{array}{c}1 L \\
V(n-B G \\
(n=22)\end{array}$ \\
\hline Median age, years (range) & $62(38-77)$ & $65(27-73)$ & $64(38-74)$ \\
\hline Age $\leq 65$ years, $n(\%)$ & $22(67)$ & $15(56)$ & $12(55)$ \\
\hline Male, $\mathrm{n}(\%)$ & $20(61)$ & $14(52)$ & $15(68)$ \\
\hline ECOG PS 0-1, n (\%) & $32(97)$ & $27(100)$ & $22(100)$ \\
\hline $\begin{array}{l}\text { Rai stage, } \mathrm{n}(\%) \\
\text { I } \\
\text { II } \\
\text { III } \\
\text { IV } \\
\text { Unknown }\end{array}$ & $\begin{array}{l}5(15) \\
2(6) \\
7(21) \\
15(46) \\
4(12)\end{array}$ & $\begin{array}{l}2(7) \\
4(15) \\
8(30) \\
5(19) \\
8(30)\end{array}$ & $\begin{array}{l}4(18) \\
6(27) \\
4(18) \\
0 \\
8(36)\end{array}$ \\
\hline Creatinine clearance $<70 \mathrm{~mL} / \mathrm{min}, \mathrm{n}(\%)$ & $8(24)$ & $11(41)$ & $5(23)$ \\
\hline $\begin{array}{l}\text { Pre-treatment TLS risk, n (\%) } \\
\text { Low } \\
\text { Medium } \\
\text { High }\end{array}$ & $\begin{array}{l}7(21) \\
16(49) \\
10(30)\end{array}$ & $\begin{array}{l}2(7) \\
19(70) \\
6(22)\end{array}$ & $\begin{array}{l}7(32) \\
10(46) \\
5(23)\end{array}$ \\
\hline $\begin{array}{l}\text { Cytogenetics, n }(\%)^{\dagger} \\
\text { del(17p) and/or TP53 mut } \\
\text { del(1lq) } \\
\text { Trisomy } 12 \\
\text { No abnormalities } \\
\text { del(13q) }\end{array}$ & $\begin{array}{l}13(42) \\
6(19) \\
4(13) \\
2(7) \\
6(19)\end{array}$ & $\begin{array}{l}2(10) \\
2(10) \\
3(14) \\
1(5) \\
13(62)\end{array}$ & $\begin{array}{l}3(17) \\
3(17) \\
2(11) \\
1(6) \\
9(50)\end{array}$ \\
\hline IGHV unmutated, $\mathrm{n} / \mathrm{N}(\%)^{\S}$ & $20 / 30(67)$ & $10 / 20(50)$ & $15 / 21(71)$ \\
\hline $\begin{array}{l}\text { Serum } \beta-2 \text { microglobulin. } \mathrm{n} / \mathrm{N}(\%) \\
\geq 3.5 \mathrm{mg} / \mathrm{mL}\end{array}$ & $8 / 16(50)$ & $5 / 8(63)$ & $5 / 8(63)$ \\
\hline $\begin{array}{l}\text { Prior therapies received, } \mathrm{n}(\%) \\
\text { Fludarabine-based treatment } \\
\text { Bendamustine or BR } \\
\text { BTKis } \\
\text { PI3Ki } \\
\end{array}$ & $\begin{array}{l}26(79) \\
4(12) \\
2(6) \\
0\end{array}$ & $\begin{array}{l}0 \\
0 \\
0 \\
0\end{array}$ & $\begin{array}{l}0 \\
0 \\
0 \\
0\end{array}$ \\
\hline
\end{tabular}

${ }^{*}$ The Ven-BG cohort did not open in R/R patients. ${ }^{\dagger}$ FISH cutoffs for positivity: $\operatorname{del}(17 \mathrm{p})>7 \%$; $\operatorname{del}(11 \mathrm{q})>6 \%$; $\operatorname{del}(13 \mathrm{q})>5.5 \%$; trisomy $12>2.5 \%$. ${ }^{\ddagger} \mathrm{A}$ modified hierarchical model was used to maximize identification of the higher risk population due to missing samples for cytogenetic assessment.The del(17p)/TP53 mut subgroup included patients with a 17p deletion by FISH and/or TP53 mutation by NGS. ${ }^{\S}$ By NGS. Cutoff for positivity $>5 \%$. R/R: relapsed/refractory; Ven: venetoclax; B: bendamustine, R: rituximab; 1 L: first-line, G: obinutuzumab; ECOG PS: Eastern Cooperative Oncology Group performance status; TLS: tumour lysis syndrome; mut: mutated; IGHV: immunoglobulin heavy-chain variable region, BTKi: Bruton's tyrosine kinase inhibitor; PI3Ki: phosphoinositide 3-kinase inhibitor; FISH: fluorescence in situ hybridization; NGS: next-generation sequencing.

(Table 1). Among patients with available baseline samples for central testing, del(17p) and/or TP53 mutation was present in $42 \%$ of $\mathrm{R} / \mathrm{R}$ and $13 \%$ of $1 \mathrm{~L}$ patients; $67 \%$ of $\mathrm{R} / \mathrm{R}$ and $60 \%$ of $1 \mathrm{~L}$ patients had unmutated immunoglobulin heavy-chain variable region (IGHV) (Table 1).

\section{Treatment exposure}

In total, $79 \%$ (26 of 33) of $\mathrm{R} / \mathrm{R}, 96 \%$ (26 of 27 ) of $1 \mathrm{~L}$ Ven-BR, and $95 \%$ (21 of 22) of 1L Ven-BG patients received Ven $400 \mathrm{mg}$. Fewer than half completed six cycles of the planned triple-drug combination (Online Supplementary Table S5). Overall, 16 R/R, 11 1L Ven-BR, and nine $1 \mathrm{~L}$ Ven-BG patients completed six bendamustine cycles. R/R patients received a median of five (range, 1-6) bendamustine cycles and six (range, 1-6) cycles of R. 1L patients received a median of five (range, 1-6) bendamustine cycles; the median number of cycles of $R$ or $G$ received was six (range, 1-6).

Median Ven treatment duration was 676 days (range, 48-1,649) in $\mathrm{R} / \mathrm{R}, 371$ days (range, 4-1,150) in $1 \mathrm{~L}$ Ven-BR, and 336 days (range, 11-620) in 1L Ven-BG patients. Sixteen $1 \mathrm{~L}$ patients, eight per arm, received Ven beyond 1 year (range, 381-1,150 days). Median relative dose intensity of Ven was $100 \%$ (range, $41-100)$ in $R / R(n=30)$, $87 \%$ (range, $37-100$ ) in $1 \mathrm{~L}$ Ven-BR $(n=26)$, and $100 \%$ (range, 33-100) in 1L Ven-BG $(n=21)$ patients (Online Supplementary Appendix).

\section{Safety}

During dose-finding, $\mathrm{R} / \mathrm{R}$ patients were enrolled to 100 mg (schedule A), 200-mg (schedule A), or 400-mg (schedule A or B) Ven cohorts; all 1L patients were included in the 400-mg (schedule A or B) Ven cohorts (Online Supplementary Table S6). The 600-mg Ven dose was not explored after review of the present study and programwide data, including phase Ib studies in CLL with Ven-R and Ven-G, where the recommended phase II dose of Ven was 400 mg. ${ }^{13,28}$ Eighteen patients received C1 treatment according to schedule $\mathrm{A}$, and 21 patients according to schedule B (Online Supplementary Table S6). No DLT were observed with either treatment schedule or combination and the MTD was not reached in the doses explored. Ven $400 \mathrm{mg}$ was selected as the recommended dose for expansion. There were no safety differences between schedules $A$ and $B$ and no TLS events were reported. After reviewing safety data from the dose-finding phase and programwide data, including from phase Ib studies with Ven- $\mathrm{G}^{13}$ and Ven-R in CLL, ${ }^{28}$ the IMC and SOC recommended schedule B (debulking with BR or BG followed by Ven), presuming increased practicality with mitigating risk of 


\section{Schedule A}
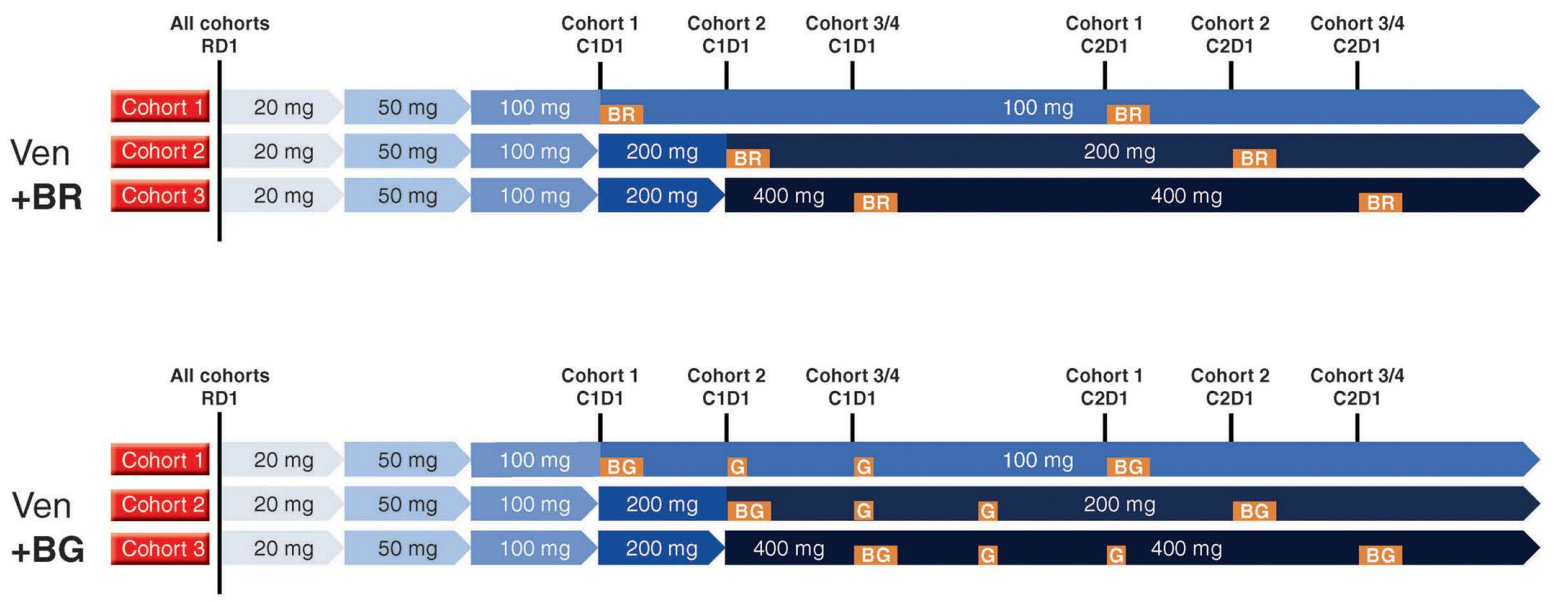

\section{Schedule B}
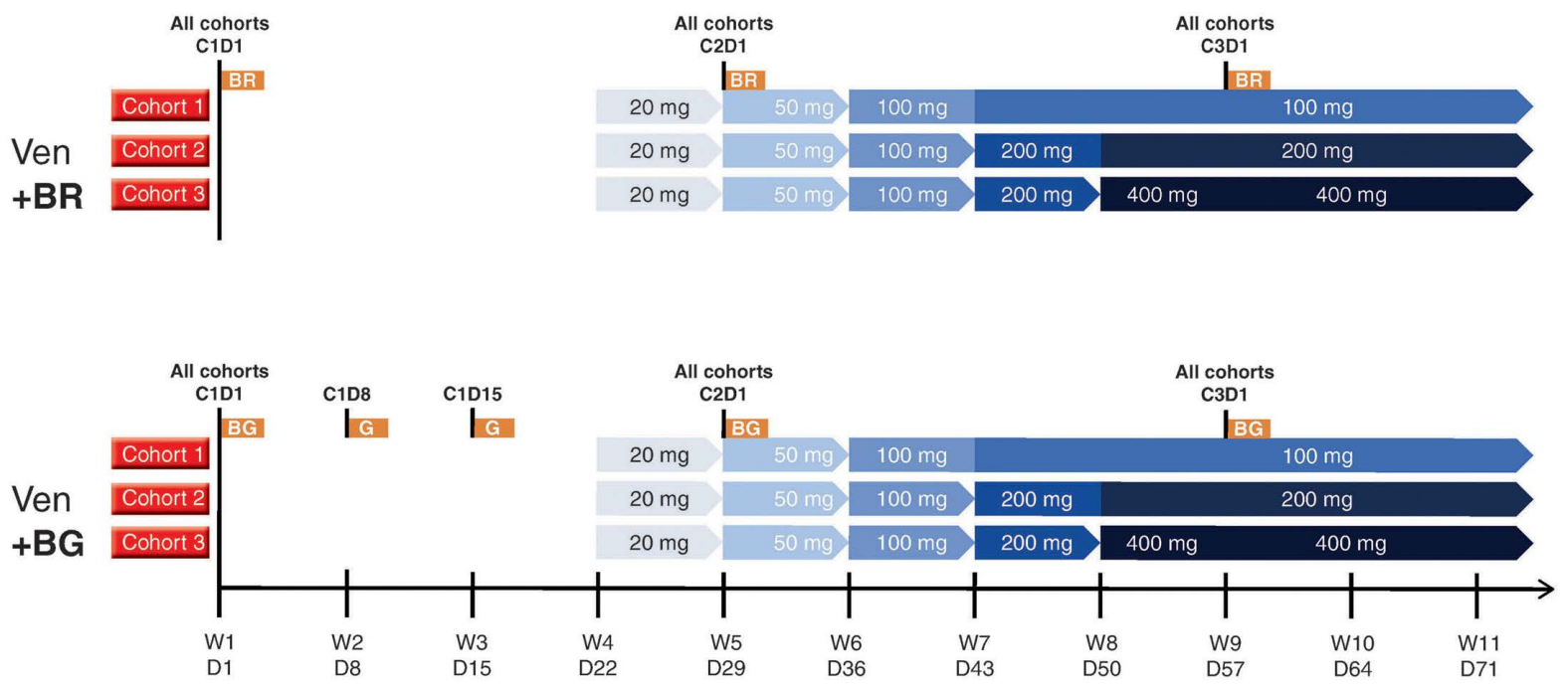

Figure 1. Treatment and dosing schedules. Schedule A: venetoclax followed by BR/BG. Schedule B: BR/BG followed by venetoclax. Schedule A with Ven-BR was explored in R/R patients before schedule $B$ in the R/R and $1 \mathrm{~L}$ populations. Data from schedule A provided safety guidance for subsequent dose-finding for patients in schedule B after a data review by the IMC and SOC. Venetoclax ramp-up: 3 weeks for the 100-mg cohort, 4 weeks for the 200 -mg cohort, and 5 weeks for the 400-mg cohort; the treatment plan consisted of venetoclax plus BR or BG (6 x 28-day cycles) in combination with venetoclax, then single-agent venetoclax; each cohort continued treatment until PD, death, or unacceptable toxicity in R/R patients, or for a total of 1-year treatment duration in 1L patients (with potential for extension if BM was positive for MRD or patient had PR). Venetoclax ramp-up and maximum cohort dose are indicated by the blue arrows. BR/BG dosing schedule: bendamustine: $90 \mathrm{mg} / \mathrm{m}^{2}$ (1L) or $70 \mathrm{mg} / \mathrm{m}^{2}$ (R/R) D1-2 per cycle for six cycles; R: $375 \mathrm{mg} / \mathrm{m}^{2}$ (C1) then $500 \mathrm{mg} / \mathrm{m}^{2}$ (C2-6) D1 per cycle; G: $100 \mathrm{mg}$ D1, $900 \mathrm{mg}$ D2, $1,000 \mathrm{mg}$ D8 and D15 C1 then 1,000 mg D1 (C2-6). Ven: venetoclax; B: bendamustine: R: rituximab; D: day; C: cycle; G: obinutuzumab; W: week; R/R: relapsed/refractory; 1L: first-line; IMC: internal monitoring committee; SOC: scientific overview committee; PD: disease progression; BM: bone marrow; MRD: minimal residual disease: PR: partial response.

TLS and a reduced number of high-risk TLS patients.

All safety-evaluable patients reported $\geq 1$ AE. All-grade infusion-related reaction events occurred in $12 \%$ of $\mathrm{R} / \mathrm{R}$ and $45 \%$ of $1 \mathrm{~L}$ patients (Table 2 ); all were grade $1-2$ excepting for two grade 3 events with Ven-BG. Serious AE were reported in $52 \%$ of $R / R$ and $53 \%$ of $1 \mathrm{~L}$ patients (Online Supplementary Table S7); grade 3-4 AE occurred in $82 \%$ of R/R and $92 \%$ of $1 \mathrm{~L}$ patients (Table 2 ). The most frequent grade 3-4 AE were neutropenia and thrombocytopenia (Table 2). Infections were mainly low grade and driven by upper respiratory tract and urinary tract infections (Table 2). Grade 3-4 infections occurred in $27 \%$ of R/R, $0 \%$ of $1 \mathrm{~L}$ Ven-BR, and $27 \%$ of $1 \mathrm{~L}$ Ven-BG patients. The frequency of grade 3-4 neutropenia was evenly dis- tributed between patients who received 1-4 or 5-6 bendamustine cycles (Online Supplementary Table S8). More grade 3-4 AE occurred during combination therapy versus monotherapy (Online Supplementary Table S9), with grade 3-4 neutropenia being reported in $65 \%$ of patients during combination therapy and $39 \%$ during monotherapy. Overall, $64 \%, 85 \%$, and $59 \%$ of patients in the R/R, $1 \mathrm{~L}$ Ven-BR, and 1L Ven-BG arms, respectively, received growth factors as prophylaxis and/or treatment (Online Supplementary Table S10); further details of growth factor treatment and response are not available.

Three TLS cases were reported during safety expansion, all in patients receiving schedule B: one laboratory and one clinical TLS occurred in two R/R patients, whereas the 
PB MRD

$\geq 3$ and $\geq 12$ months after $R$
PB MRD $\geq 12$ months

after $R$ by cycles of bendamustine
BM MRD

at any time

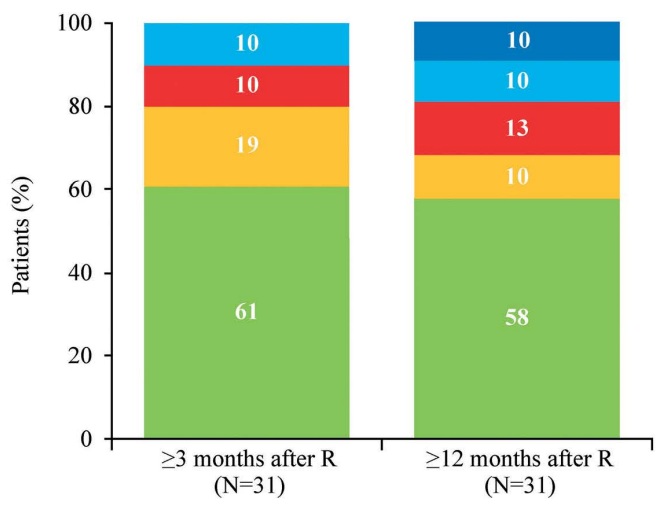

Undetectable MRD

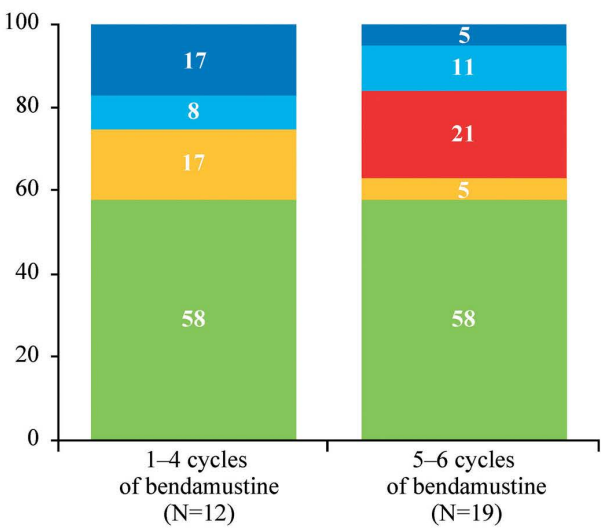

$(\mathrm{N}=12)$
$(\mathrm{N}=19)$

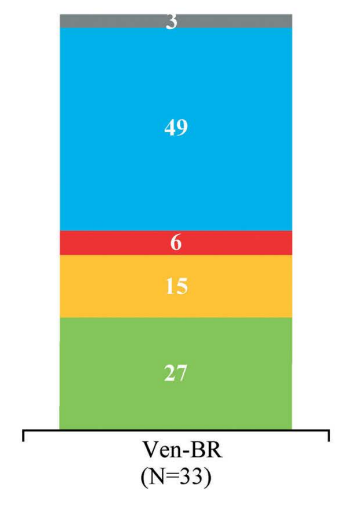

Undetermined

B PB MRD
$\geq 3$ and $\geq 9$ months after Ven

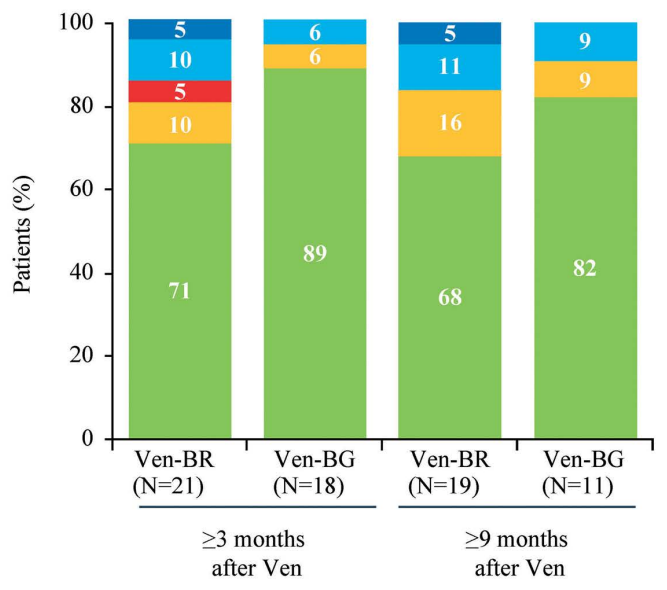

High-level MRD

Discontinued
PB MRD $>3$ months after Ven by cycles of bendamustine

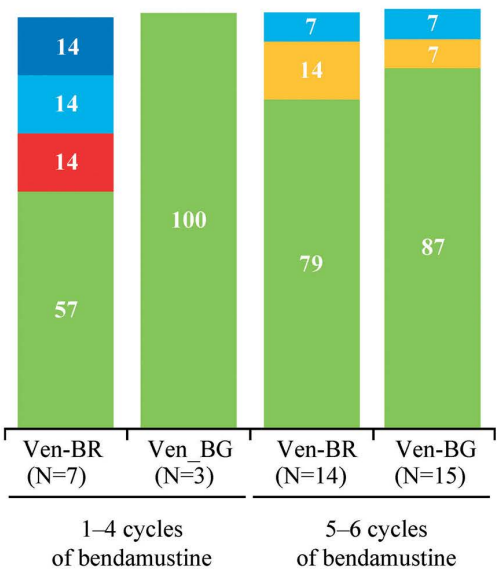

BM MRD

at any time

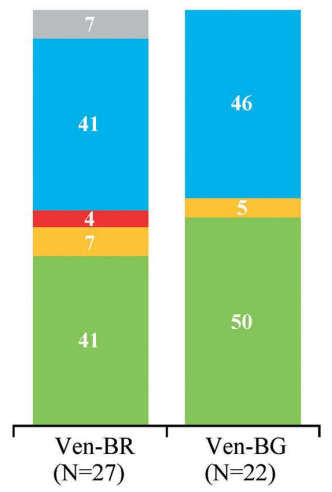

Undetectable MRD Low-level MRD

High-level MRD

Discontinued

Missing

Undetermined

Figure 2. Minimal residual disease status by flow in peripheral blood and bone marrow in the (a) relapsed/refractory population and (b) untreated population. Discontinued includes patients who discontinued study due to PD, death, or AE (if applicable) before achieving the specified landmark time point; missing includes patients who reached the time-point but had no sample available for MRD analysis; undetermined includes patients with MRD level $<10^{-4}$, but $<200,000$ leukocytes analyzed. uMRD: $<1 \mathrm{CLL}$ cell per $10^{4}$ mononuclear cells; low-level MRD: $\geq 1 \mathrm{CLL}$ cell per $10^{4}$ mononuclear cells to $<1 \mathrm{CLL}$ cell per $10^{4}$ mononuclear cells; high-level MRD: $\geq 1$ CLL cell per $10^{2}$ mononuclear cells. MRD: minimal residual disease; PB: peripheral blood; BM: bone marrow; R/R: relapsed/refractory; $1 \mathrm{~L}$ first-line; R: rituximab; B: bendamustine; Ven: venetoclax; G: obinutuzumab; PD: disease progression; AE: adverse event; uMRD: undetectable MRD; CLL: chronic lymphocytic leukemia.

other laboratory TLS occurred in a 1L Ven-BG patient (Online Supplementary Table S11). Both laboratory TLS events occurred prior to initiation of Ven. The clinical TLS event occurred on day 29 after administration of Ven $50 \mathrm{mg}$ (D1 of the second BR cycle); it was diagnosed due to clinical symptoms of hypotension and dyspnoea with hyperkalaemia (potassium: $7.6 \mathrm{mmol} / \mathrm{L}$ ) and elevated phosphorus levels $(2.97 \mathrm{mmol} / \mathrm{L}$ ). Electrocardiogram data were not provided by the center. BR was permanently discontinued and single-agent Ven was re-introduced on study day 61 without further incidence of TLS. All TLS events resolved with standard-of-care measures; the two laboratory events did not lead to permanent discontinuation of any study drug.

Bendamustine was permanently discontinued due to $\mathrm{AE}$ in $33 \%$ of $\mathrm{R} / \mathrm{R}$ and $37 \%$ of $1 \mathrm{~L}$ patients (Online Supplementary
Table S12). The most common AE leading to permanent bendamustine withdrawal was neutropenia. Ven was interrupted and/or reduced due to $\mathrm{AE}$ in $67 \%$ of $\mathrm{R} / \mathrm{R}$ and $82 \%$ of $1 \mathrm{~L}$ patients, most frequently due to neutropenia $(\mathrm{R} / \mathrm{R}$, $36 \%$ of patients; $1 \mathrm{~L}$ Ven-BR, $63 \%$; $1 \mathrm{~L}$ Ven-BG, $46 \%$ ) (Online Supplementary Table S12). Ven was permanently discontinued due to $A E$ in $27 \%$ of $R / R$ and $29 \%$ of $1 L$ patients (Online Supplementary Tables S12 and S13).

Two deaths were reported: one due to stage 4, highgrade malignant hemangioendothelioma in a $R / R$ patient, resulting in multiple organ failure on study day 144, and one due to hemorrhagic transformation of stroke on study day 83 in a $1 \mathrm{~L}$ Ven-BR patient with history of hypertension and concomitant grade 3 treatmentrelated thrombocytopenia (platelet levels were normal at screening). 
Table 2. Treatment-emergent adverse events.

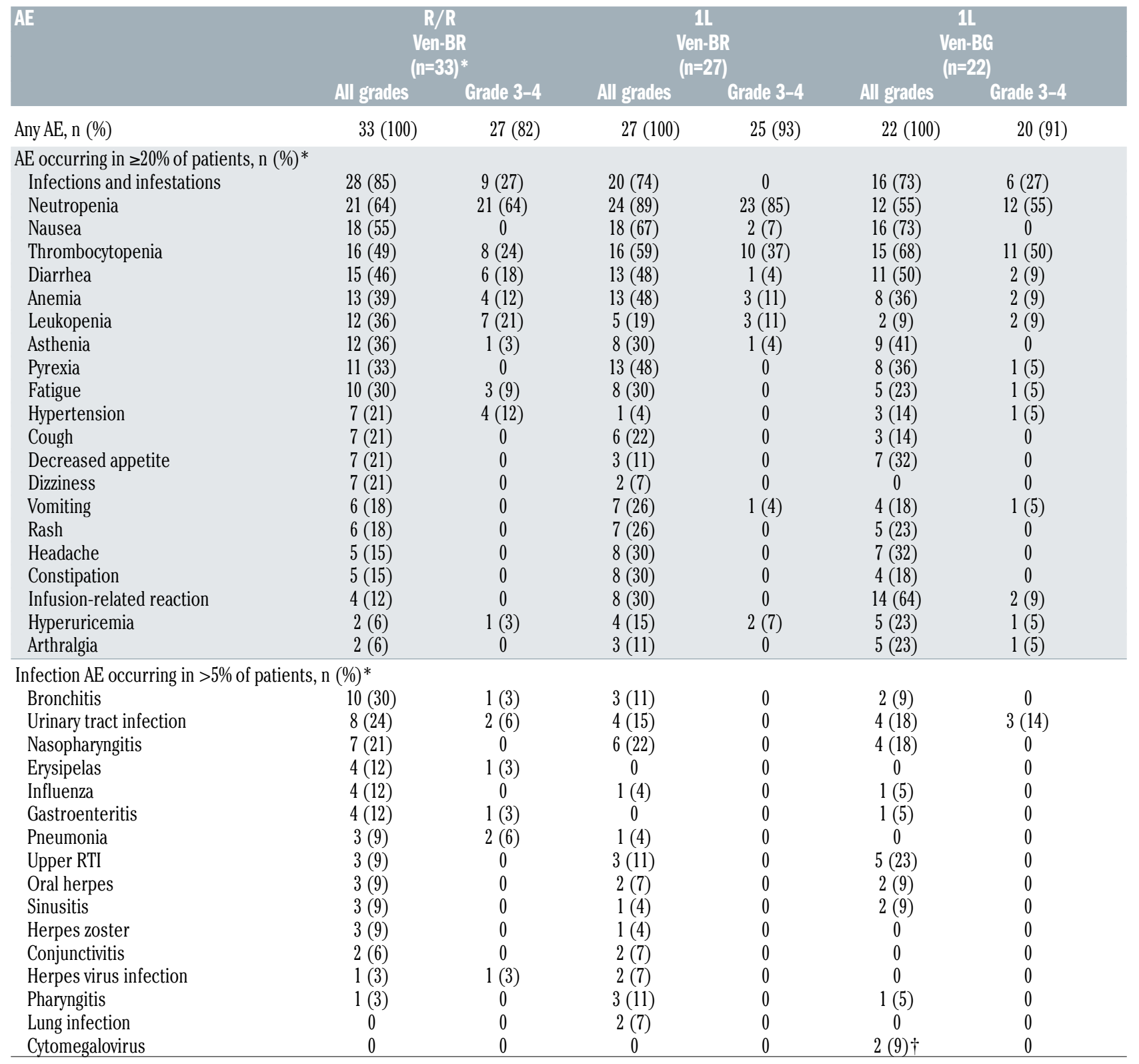

Data include all investigator-reported adverse events (AE), regardless of relationship to study drug. AE occurring in $\geq 20 \%$ of patients are listed by MedDRA PT. Infection AE occurring in $>5 \%$ patients are listed by MedDRA Systems Organ Class and PT. *Any-grade AE in any population or treatment arm. ${ }^{\dagger}$ Details of the diagnosis of these events were not reported, so it is not known whether they were symptomatic or detected via screening. R/R: relapsed/refractory; V: venetoclax; B: bendamustine; R: rituximab; 1L: first-line; G: obinutuzumab; RTI: respiratory tract infection; MedDRA: Medical Dictionary for Regulatory Activities; PT: preferred term; SOC: System Organ Class

\section{Efficacy}

Overall response rate was $91 \%$ (30 of 33 ) in $\mathrm{R} / \mathrm{R}$ patients (including $42 \%$ [14 of 33] with complete response [CR] or $\mathrm{CR}$ with incomplete hematologic recovery [CRi]). All 1L patients responded (overall response rate 100\%; including $44 \%$ [12 of 27] CR/CRi for Ven-BR, and 68\% [15 of 22] CR/CRi for Ven-BG). Responses were similar regardless of cytogenetic status, IGHV status or whether patients received 1-4 or 5-6 bendamustine cycles (Table 3).

Landmark PB uMRD rates were $58 \%$ (18 of 31$) \geq 12$ months after last $\mathrm{R}$ dose in $\mathrm{R} / \mathrm{R}$ patients, and $71 \%$ (15 of 21 ) and $89 \%$ (16 of 18) $\geq 3$ months after last Ven dose with 1L Ven-BR and Ven-BG, respectively (Figure 2). These rates were observed regardless of whether patients received $1-4$ or $5-6$ bendamustine cycles and were maintained over time (Figure 2).
In the $\mathrm{R} / \mathrm{R}$ population, after a median follow-up of 26 months (range, 24-31) from the last $\mathrm{R}$ dose, among patients who reached $\geq 24$ months after the last $R$ dose plus those who discontinued earlier, the PB uMRD rate was sustained at $37 \%$ (10 of 27 ). For the $1 \mathrm{~L}$ population, $\geq 12$ months after completion of all treatment (last Ven dose; median follow-up 14 months [range, 12-18]), the PB uMRD rate was sustained at $67 \%$ (12 of 18) for Ven-BR and $90 \%$ (9 of 10) for Ven-BG. 41-49\% of patients had missing samples for BM MRD analysis. Among patients with samples available, the rate of $\mathrm{uMRD}$ as best MRD response in the BM was $53 \%$ ( 9 of 17), 69\% (11 of 16), and $92 \%$ (11 of 12 ) in the R/R, $1 L$ Ven-BR, and $1 L$ Ven-BG arms, respectively. Among patients with $\mathrm{PB}$ and $\mathrm{BM}$ postbaseline paired samples from the same day, concordance between a patient's MRD status determined from $\mathrm{PB}$ and 
BM was high and similar across the arms (Online Supplementary Table S14).

MRD kinetics in individual patients are shown in Figure 3. Among $24 \mathrm{R} / \mathrm{R}$ patients who achieved $\mathrm{PB} \mathrm{uMRD}$ in $\geq 1$ assessment and had subsequent $\mathrm{PB}$ MRD assessment(s), nine converted to MRD positivity (low or high levels) in two consecutive assessments, of whom three experienced $\mathrm{PD}$ as of the current follow-up. In $421 \mathrm{~L}$ patients who achieved $\mathrm{PB}$ uMRD in $\geq 1$ assessment and had subsequent $\mathrm{PB} M R D$ assessment(s), five converted to MRD positivity, only one of whom experienced PD. Median time to first MRD conversion (from the first $\mathrm{PB}$ uMRD result) was 360

A

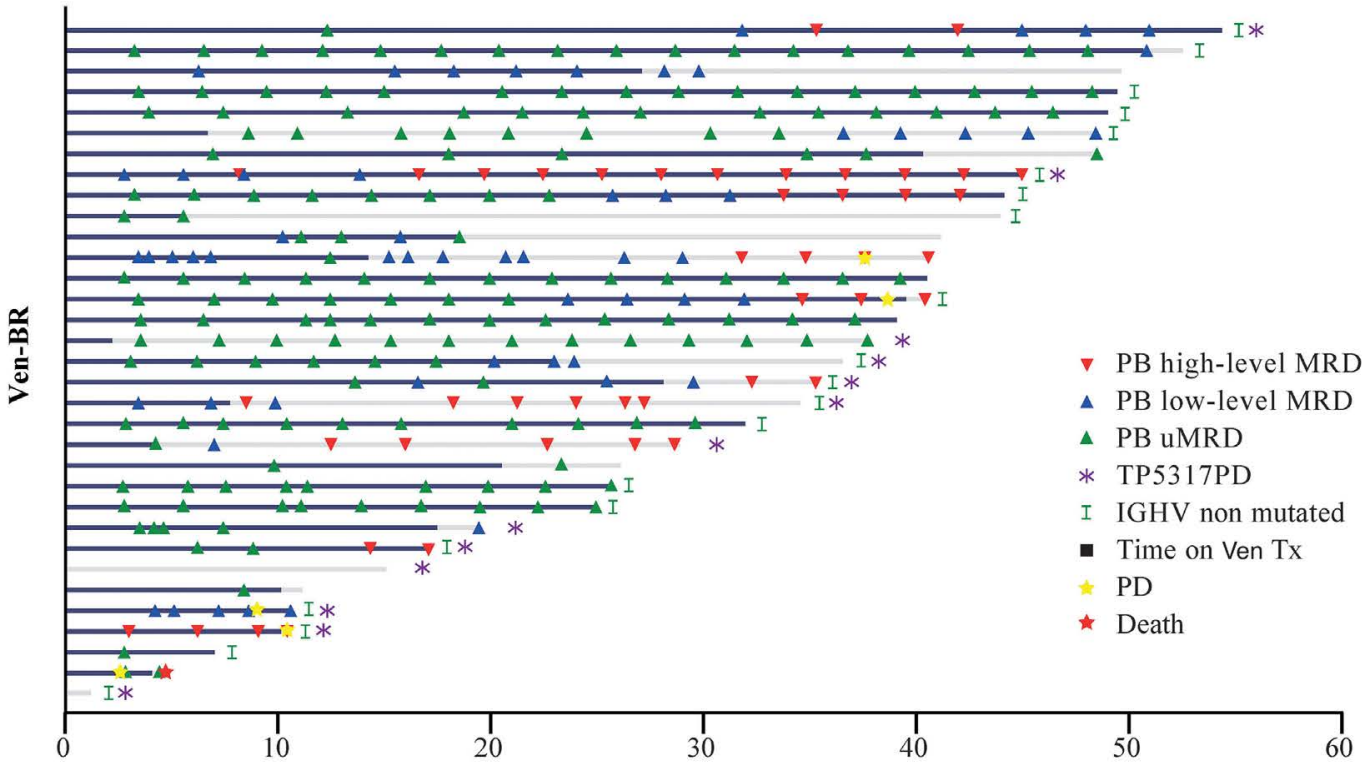

Time (months)

B

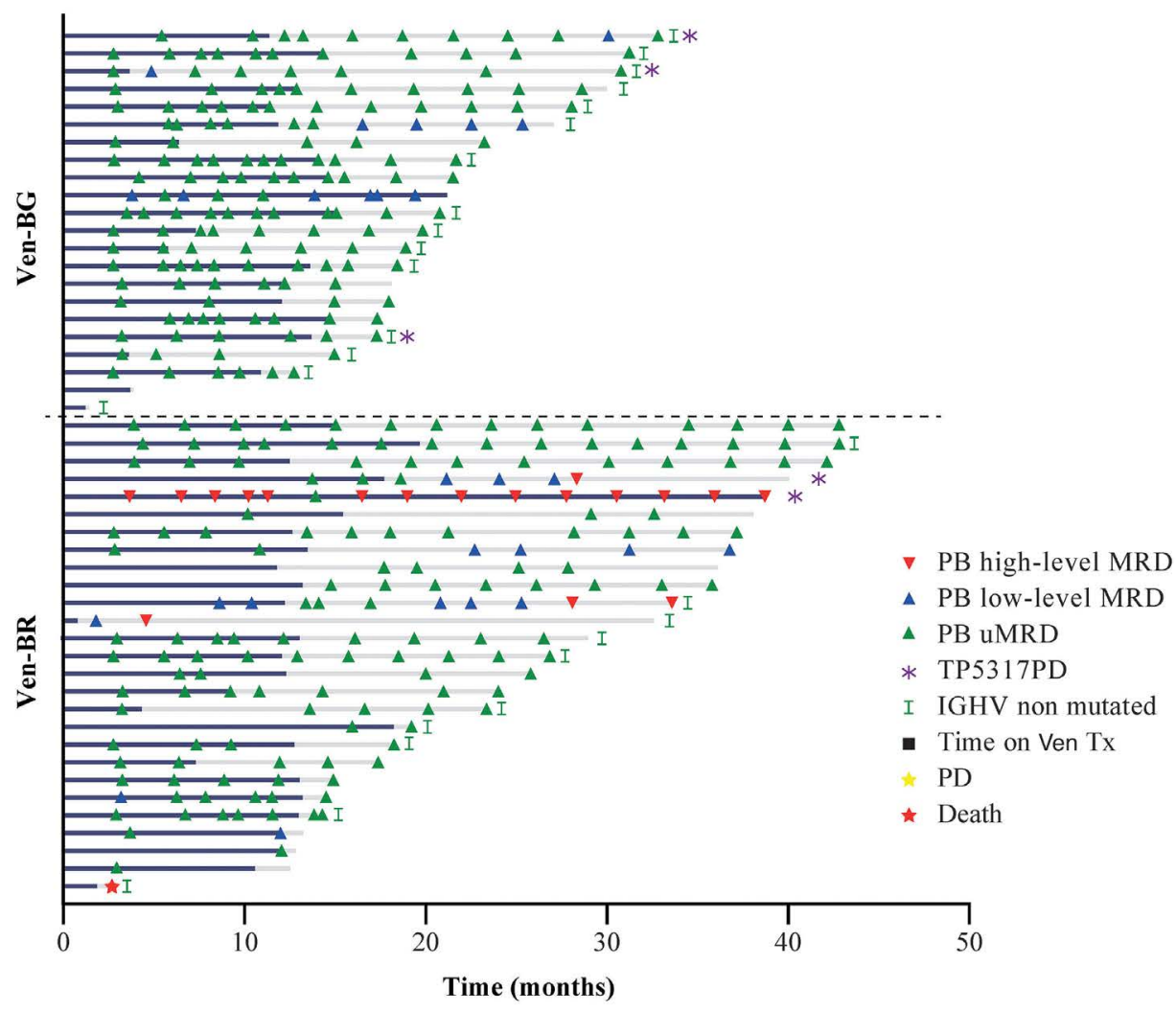

Figure 3. Minimal residual disease kinetics in individual patients in the (a) relapsed/refractory population and (b) first-line population. Undetectable minimal residual disease (UMRD) was defined as $<1$ chronic lymphocytic leukemia (CLL) cell per $10^{4}$ mononuclear cells in samples with a minimum of 200,000 leukocytes $\left(<10^{-4}\right)$. Low-level MRD was defined as between $1 \mathrm{CLL}$ cell per $10^{4}$ and 1 cell per $10^{2}$ mononuclear cells $\left(\geq 10^{-4}-<10^{-2}\right)$. High-level MRD was defined as $\geq 1 \mathrm{CLL}$ cell per $10^{2}$ mononuclear cells $\left(\geq 10^{-2}\right)$ MRD: minimal residual disease; R/R: relapsed/refractory; 1 : first-line; Ven: venetoclax; $B$ : bendamustine; $R$ : rituximab; PB: peripheral blood; BM: bone marrow; IGHV: immunoglobulin heavy-chain variable region; Tx: treatment; PD: disease progression; G: obinutuzumab; uMRD: undetectable MRD; CLL: chronic lymphocytic leukemia. 
days (range, 42-848) and 224 days (range, 77-600) in the $\mathrm{R} / \mathrm{R}$ and $1 \mathrm{~L}$ Ven-BR arms, respectively. For the patient in the $1 \mathrm{~L}$ Ven-BG arm who experienced MRD conversion, time from first $\mathrm{PB}$ uMRD result to conversion was 324 days.

PFS is shown in Figure 4. After a median observation time of 36.5 months (range, 1-54) and 21.6 months (range, $1-43$ ) in the R/R and $1 \mathrm{~L}$ populations, respectively, estimated 24-month PFS was $87 \%$ (95\% Confidence Interval [CI]: 74-99) for R/R, 96\% (95\% CI: 89-100) for 1L Ven-BR, and $100 \%$ (95\% CI: 100-100) for 1L Ven-BG patients. Seven $\mathrm{PD}$, including two cases of Richter's transformation to diffuse large B-cell lymphoma, were reported in the R/R population. Only one PD was observed with 1L Ven-BR. No PD were reported with $1 \mathrm{~L}$ Ven-BG. Among the eight patients who progressed, four (all R/R) had baseline del(17p) and/or TP53 mutation.

\section{Discussion}

In this phase Ib study, $400 \mathrm{mg}$ Ven daily was selected, in combination with standard doses of BR/BG, for safety expansion in $\mathrm{R} / \mathrm{R}$ and $1 \mathrm{~L}$ CLL patients. While no MTD was reached during dose escalation up to $400 \mathrm{mg}$, both triplet combination regimens with bendamustine in the expansion phase showed increased toxicity versus Ven-R and Ven-G alone, ${ }^{6-8}$ leading to low tolerability, as seen with high rates of bendamustine discontinuation. The fact that fewer than half of all patients were able to complete the full six cycles of bendamustine (B) may at least partially explain the apparent lack of efficacy seen here in comparison with the efficacy of backbone Ven-R or Ven-G, despite the preclinical rationale.

Neutropenia was the most important toxicity in triplet combinations in both $1 \mathrm{~L}$ and R/R CLL populations. Rates of grade 3-4 neutropenia, however, were generally consistent with those observed with Ven-R in R/R CLL in the MURANO trial (58\% [112 of 194]), ${ }^{7}$ with Ven-G in 1L CLL in CLL14 (53\% [112 of 212]), ${ }^{8}$ and with ibrutinib plus BR in R/R CLL in the HELIOS study (54\% [154 of 287]). ${ }^{11,14}$ The small sample size in the $1 \mathrm{~L}$ Ven-BR arm could have contributed to the numerically high rates of grade 3-4 neutropenia in this arm and limits the ability to make comparisons. Despite a high rate of neutropenia, infections were mainly low grade and driven by upper respiratory tract and urinary tract infections. In $1 \mathrm{~L}$ populations, grade 3-4 infections appeared to be higher with Ven-BG ( $27 \%$ [6 of 22$]$ ) than Ven-BR ( $0 \%$ [0 of 27$])$, which is probably a reflection of the non-randomized nature of the study and the small numbers involved. However, a high rate of infections has been seen with BG combinations in CLL $\left(21.4 \%\right.$ grade $\geq 3$ in the GREEN phase IIIb study), ${ }^{29}$ and in the randomized phase III GALLIUM study of BG versus $\mathrm{BR}$ in follicular lymphoma, grade 3-5 infection rates were also higher with $\mathrm{BG}$ than $\mathrm{BR}(26 \%$ vs. $20 \%) .{ }^{30}$ Grade 3-4 infection rates were higher in the present study than those seen in the CLL14 trial with Ven-G $(17.5 \%)^{8}$ and in the CLL2-BAG trial during induction with G and Ven $(19 \%$ [six of 31$]) .{ }^{31}$ The grade $3-4$ infection rate in the $\mathrm{R} / \mathrm{R}$ population was higher than that seen with Ven- $\mathrm{R}$ in MURANO (18\% [34 of 194]), ${ }^{7}$ but similar to the rate of grade $\geq 3$ infection reported with ibrutinib plus $B R$ in HELIOS (29\% [83 of 287]). ${ }^{11}$ Direct between-study comparisons are difficult to interpret given differences in sample sizes, baseline characteristics, treatment duration, and follow-up. However, addition of bendamustine to Ven-R or Ven-G in the current study led to significantly increased infection rates and reduced the tolerability of these combinations. Increased toxicity with bendamustine-containing combinations with Ven is also seen in NHL, ${ }^{32,33}$ limiting the use of these combinations with Ven in future CLL treatment strategies.

The higher CR rates observed with $1 \mathrm{~L}$ Ven-BG than Ven-BR were consistent with previous demonstration of superior efficacy of $G$ compared with $R$ when used in combination with chemotherapy. ${ }^{34}$ Similarly, landmark ( $\geq 3$ and $\geq 9$ months after treatment) PB uMRD rates were higher in $1 \mathrm{~L}$ Ven-BG than $1 \mathrm{~L}$ and $\mathrm{R} / \mathrm{R}$ Ven-BR patients. Around half of patients in all arms did not provide $B M$

Table 3. Response according to 2008 International Workshop on Chronic Lymphocytic Leukemia Guidelines in the untreated (1L) or relapsed/refractory populations.

\begin{tabular}{|c|c|c|c|c|c|c|c|c|c|c|}
\hline \multirow[t]{2}{*}{ Patients } & \multicolumn{6}{|c|}{$\begin{array}{l}\text { Responses per } \\
\text { cytogenetic status* }\end{array}$} & \multicolumn{2}{|c|}{$\begin{array}{l}\text { Responses per } \\
\text { IGHV status }\end{array}$} & \multicolumn{2}{|c|}{$\begin{array}{c}\text { Responses per number of } \\
\text { cycles of bendamustine } \\
\text { received }\end{array}$} \\
\hline & $\begin{array}{l}\text { Entire } \\
\text { cohort }\end{array}$ & $\begin{array}{l}\text { del(17p) and/or } \\
\text { TP53 mut }\end{array}$ & $\operatorname{del}(11 \mathrm{q})$ & $\begin{array}{c}\text { Trisomy } \\
12\end{array}$ & None & $\operatorname{del}(13 q)$ & Mutated & Unmutated & d $1-4$ & 5-6 \\
\hline \multicolumn{11}{|c|}{ R/R patients, n (\%) } \\
\hline Ven-BR, $\mathrm{n}^{\dagger}$ & 33 & 12 & 6 & 4 & 2 & 6 & 3 & 19 & 13 & 20 \\
\hline ORR & $30(91)$ & $11(85)$ & $6(100)$ & $4(100)$ & $2(100)$ & $6(100)$ & $3(100)$ & $19(100)$ & $11(85)$ & $19(95)$ \\
\hline CR/CRi & $14(42)$ & $3(23)$ & $4(67)$ & $3(75)$ & $2(100)$ & $2(33)$ & $3(100)$ & $7(37)$ & $5(39)$ & $9(45)$ \\
\hline PR & $16(49)$ & $8(62)$ & $2(33)$ & $1(25)$ & 0 & $4(67)$ & 0 & $12(63)$ & $6(46)$ & $10(50)$ \\
\hline \multicolumn{11}{|c|}{ 1L patients, n (\%) } \\
\hline Ven-BR, n & 27 & 2 & 2 & 3 & 1 & 13 & 8 & 10 & 9 & 18 \\
\hline ORR & $27(100)$ & $2(100)$ & $2(100)$ & $3(100)$ & $1(100)$ & $13(100)$ & $8(100)$ & $10(100)$ & $9(100)$ & $18(100)$ \\
\hline CR/CRi & $12(44)$ & $2(100)$ & $2(100)$ & $1(33)$ & 0 & $5(39)$ & $5(63)$ & $5(50)$ & $3(33)$ & $9(50)$ \\
\hline PR & $15(56)$ & 0 & 0 & $2(67)$ & $1(100)$ & $8(62)$ & $3(38)$ & $5(50)$ & $6(67)$ & $9(50)$ \\
\hline Ven-BG, n & 22 & 3 & 3 & 2 & 1 & 9 & 3 & 15 & 6 & 16 \\
\hline ORR & $22(100)$ & $3(100)$ & $3(100)$ & $2(100)$ & $1(100)$ & $9(100)$ & $3(100)$ & $15(100)$ & $6(100)$ & $16(100)$ \\
\hline CR/CRi & $15(68)$ & $2(67)$ & $3(100)$ & $1(50)$ & $1(100)$ & $6(67)$ & $2(67)$ & $11(73)$ & $6(67)$ & $11(69)$ \\
\hline PR & $7(32)$ & $1(33)$ & 0 & $1(50)$ & 0 & $3(33)$ & $1(33)$ & $4(27)$ & $2(33)$ & $5(31)$ \\
\hline
\end{tabular}

* Responses by cytogenetic abnormalities according to the modified hierarchical model in patients with samples available for cytogenetic assessment. ${ }^{\dagger}$ The Ven-BG cohort was not explored in R/R patients. CLL: chronic lymphocytic leukemia; R/R: relapsed/refractory; $1 \mathrm{~L}$ : first-line; mut: mutated;Ven: venetoclax; B: bendamustine; R: rituximab ORR: overall response rate; $\mathrm{CR}$ : complete response; $\mathrm{CRi}$ :complete response with incomplete hematologic recovery; PR: partial response; G: obinutuzumab. 


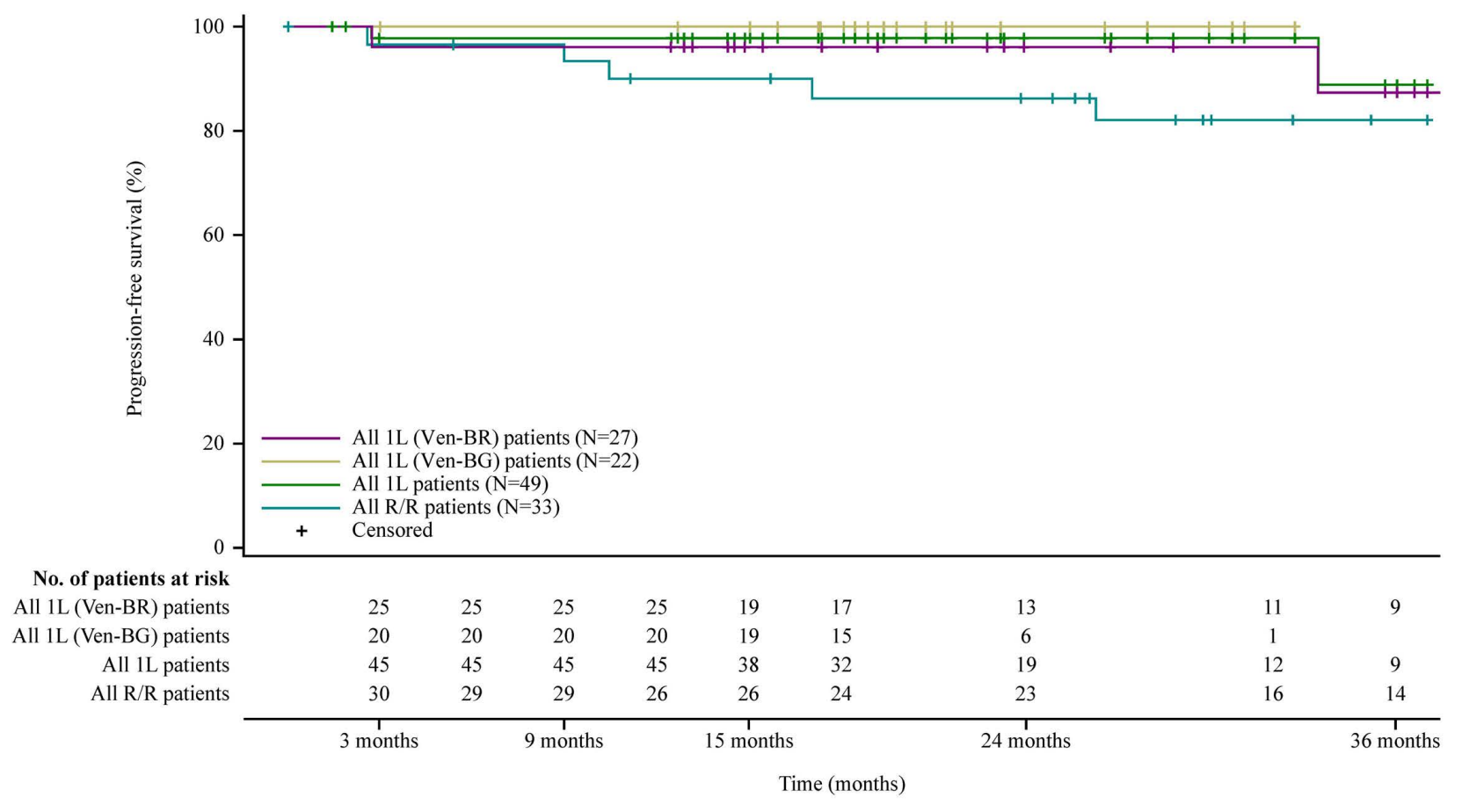

Figure 4. Progression-free survival. 1L: first-line; Ven: venetoclax; B: bendamustine; R: rituximab; G: obinutuzumab; R/R: relapsed/refractory.

samples for MRD assessment (an exploratory study endpoint), which affects the interpretability of BM uMRD rates. However, there was a high concordance between $\mathrm{BM}$ and $\mathrm{PB}$ results in paired samples. This was consistent with the concordance between PB and BM MRD determination seen with Ven treatment in the MURANO $(86 \%)$ and CLL14 (87\%) studies, ${ }^{6,35}$ suggesting that PB MRD status reflects BM MRD status in Ven-treated patients. High $\mathrm{PB}$ UMRD rates observed were consistent with those seen in phase II and III trials with Ven-R, ${ }^{6}$ Ven-G, ${ }^{8,35}$ and Ven plus ibrutinib ${ }^{36}$ and higher than reported previously with $\mathrm{BG}^{20}$ or $\mathrm{BR}$ alone in $1 \mathrm{~L}$ patients, ${ }^{37}$ highlighting the efficacy of Ven-R and Ven-G alone, independent of the addition of bendamustine. However, cross-trial comparisons with this phase Ib study must be made with caution, and previous analyses were performed in the respective intention-totreat populations, as opposed to the subgroup of evaluable patients we had to use, and overall sample sizes were much larger.

Re-emergence of $\mathrm{MRD}$ in $\mathrm{PB}$, which was observed in a minority of patients, mainly in the $\mathrm{R} / \mathrm{R}$ population, did not appear to be associated with immediate development of PD. Larger trials are needed to identify patients most likely to convert to MRD positivity, the impact and time from the MRD conversion on the appearance of clinical progression, and the feasibility of time-limited therapy in CLL.

The 2 -year PFS rate reported here in the R/R group with Ven-BR is similar to that seen with Ven-R in MURANO $(85 \%),{ }^{7}$ suggesting no benefit from the addition of bendamustine overall. In contrast, 2-year PFS in $1 \mathrm{~L}$ patients was higher than that reported with Ven-G in CLL14 $(88 \%){ }^{8}$ however, the two studies are very different and it should be noted that the CLL14 study recruited patients with co-existing conditions, whereas the population of the present study was relatively young, with a good performance status, and numbers were small. Also, 16 of 49 1L patients continued Ven beyond 1 year.
A limitation of this study was the small sample size in each arm and non-randomized allocation to verify significant safety and efficacy differences across triplet combinations and across the number of bendamustine cycles received. In addition, most patients were $<65$ years old with creatinine clearance $\geq 70 \mathrm{~mL} / \mathrm{min}$, with a good performance status, which may have affected some of the study outcomes.

$400 \mathrm{mg}$ daily Ven given with standard-dose BR or BG increased toxicity compared with published data for Ven$R$ and Ven-G, without an apparent efficacy benefit for the addition of bendamustine. The question remains whether there is an optimal number of bendamustine cycles that would be beneficial for all or for a particular subgroup of CLL patients, or whether the addition of bendamustine (with a different dose/schedule) to Ven-R or Ven-G could improve clinical outcomes without impaired tolerability. However, considering the extent of the toxicity reported here, exploration of lower bendamustine doses is expected to have a limited role. Indeed, in the era of novel targeted agents replacing the standard chemo-immunotherapy regimens and demonstrating improved safety and efficacy profiles, there seems to be minimal need to add standard chemotherapy to novel regimens.

\section{Disclosures}

SS acts as a consultant, has received honoraria and research funding, sits on the board of directors or advisory committee of AbbVie, Gilead, GSK, Roche, Janssen, Novartis, Celgene, Amgen, Genentech; FM acts as a consultant for Epizyme, Roche/Genentech, Celgene, Gilead, has received honoraria from Roche/Genentech, Celgene, Gilead, BMS, Janssen, sits on the board of directors or advisory committee of Roche/Genentech, Celgene, Gilead, Servier, BMS, Janssen; C$M W$ acts as a consultant, has received honoraria and research funding from Roche, Mundipharma, MorphoSys, Janssen, Gilead, AbbVie, Pharmacyclics, Genentech, GlaxoSmithKline, 
has received travel support from Roche, MorphoSys, Janssen, Gilead, AbbVie, Pharmacyclics, Genentech, GlaxoSmithKline; GC acts a consultant for Celgene, Roche, has received honoraria from Celgene, Sanofi, Roche, Janssen, Gilead; MH has received honoraria and research funding from AbbVie, Celgene, Gilead, Janssen, Mundipharma, Pharmacyclics, Roche; BE has received honoraria, research funding, and travel support from AbbVie, ArQule, BeiGene, Celgene, Gilead, Janssen, Mundipharma, Novartis, Roche; MFK acts as a consultant and sits on the board of directors or advisory committee of Genentech, Roche, AbbVie; TG has non conflicts of interest to disclose; GL has received research funding from Genentech, Stem Line, BI, Novartis, Beckman, Coulter; YJ and MM are employed by Genentech; YJ has equity ownership of Genentech; MM has ownership interests non-PLC in Roche; $H H, D S P$, and KH are employed by Roche; WS is employed by AbbVie; GS acts as a consultant for Novartis, Roche, has received honoraria from Novartis, Roche, Celgene, AbbVie, Acerta, Amgen, Epizyme, Gilead, Janssen, Merck, Morphosys, Pfizer, Servier, Takeda, BMS, sits on the advisory board of Celgene, Gilead, Janssen, Servier, BMS, and has received research funding from Roche, Celgene.

\section{Contributions}

$S S, F M, C-M W, G C, M H, B E, M F K, G L, M M$, and GS designed the study; SS, FM, C-MW, GC, MH, BE, MFK, TG, $G L$, and GS collected and assembled the data; $S S, F M, C-M W$, GC, MH, BE, MFK, GL, YJ, HH, DSP, WS, KH, MM, and
$G S$ analyzed the data and were involved in the writing process; $S S, F M, C-M W, G C, M H, B E, M F K, T G, G L, Y J, H H, D S P$, WS, KH, MM, and GS interpreted the data, participated in manuscript development, and gave final approval.

\section{Acknowledgments and Funding}

Special thanks go to the patients and their families, investigators, study coordinators, and support staff, and all GO28440 study team members. Venetoclax is being developed in collaboration between Genentech, Inc. and AbbVie. Genentech, Inc. and AbbVie provided financial support for the study and participated in the design, study conduct, and data analysis and interpretation. Third party medical writing and editorial assistance, under the direction of the authors, was provided by Kate Rijnen, a contract Medical Writer at Ashfield MedComms (Macclesfield, UK), an Ashfield Health company, and funded by F. HoffmannLa Roche Ltd.

\section{Data-sharing statement}

Qualified researchers may request access to individual patient level data through the clinical study data request platform (https://vivli.org/). Further details on Roche's criteria for eligible studies are available here (https://vivli.org/members/ourmembers/). For further details on Roche's Global Policy on the Sharing of Clinical Information and how to request access to related clinical study documents, see here (https://www.roche.com/ research_and_development/who_we_are_how_we_work/clinical_trials/our_commitment_to_data_sharing.htm

\section{References}

1. Gribben JG, O'Brien S. Update on therapy of chronic lymphocytic leukemia. J Clin Oncol. 2011;29(5):544-550.

2. Jain N, O'Brien S. Initial treatment of CLL: integrating biology and functional status. Blood. 2015;126(4):463-470.

3. O'Brien S, Furman RR, Coutre S, et al. Single-agent ibrutinib in treatment-naive and relapsed/refractory chronic lymphocytic leukemia: a 5-year experience. Blood. 2018;131(17):1910-1919.

4. Brown JR, Byrd JC, Coutre SE, et al. Idelalisib, an inhibitor of phosphatidylinositol 3-kinase p110delta, for relapsed/refractory chronic lymphocytic leukemia. Blood. 2014;123(22):3390-3397.

5. Stilgenbauer S, Eichhorst B, Schetelig J, et al. Venetoclax for patients with chronic lymphocytic leukemia with $17 p$ deletion: results from the full population of a phase II pivotal trial. J Clin Oncol. 2018;36(19): 1973-1980.

6. Kater AP, Seymour JF, Hillmen P, et al. Fixed duration of venetoclax-rituximab in relapsed/refractory chronic lymphocytic leukemia eradicates minimal residual disease and prolongs survival: post-treatment follow-up of the MURANO phase III study. J Clin Oncol. 2019;37(4):269-277.

7. Seymour JF, Kipps TJ, Eichhorst B, et al. Venetoclax-rituximab in relapsed or refractory chronic lymphocytic leukemia. N Engl J Med. 2018;378(12):1107-1120.

8. Fischer K, Al-Sawaf O, Bahlo J, et al. Venetoclax and obinutuzumab in patients with CLL and coexisting conditions. N Engl J Med. 2019;380(23):2225-2236.

9. Burger JA, Sivina M, Jain N, et al. Randomized trial of ibrutinib vs ibrutinib plus rituximab in patients with chronic lymphocytic leukemia. Blood. 2019;
133(10):1011-1019.

10. Furman RR, Sharman JP, Coutre SE, et al. Idelalisib and rituximab in relapsed chronic lymphocytic leukemia. N Engl J Med. 2014; 370(11):997-1007.

11. Chanan-Khan A, Cramer P, Demirkan F, et al. Ibrutinib combined with bendamustine and rituximab compared with placebo, bendamustine, and rituximab for previously treated chronic lymphocytic leukaemia or small lymphocytic lymphoma (HELIOS): a randomised, double-blind, phase 3 study. Lancet Oncol. 2016;17(2):200-211.

12. Zelenetz AD, Barrientos JC, Brown JR, et al. Idelalisib or placebo in combination with bendamustine and rituximab in patients with relapsed or refractory chronic lymphocytic leukaemia: interim results from a phase 3 , randomised, double-blind, placebo-controlled trial. Lancet Oncol. 2017;18(3):297-311.

13. Flinn IW, Gribben JG, Dyer MIS, et al. Phase $1 \mathrm{~b}$ study of venetoclax-obinutuzum $\mathrm{ab}$ in previously untreated and relapsed/refractory chronic lymphocytic leukemia. Blood. 2019;133(26):2765-2775.

14. Fraser G, Cramer P, Demirkan F, et al. Updated results from the phase 3 HELIOS study of ibrutinib, bendamustine, and rituximab in relapsed chronic lymphocytic leukemia/small lymphocytic lymphoma. Leukemia. 2019;33(4):969-980.

15. US Food and Drug Administration. FDA approves venetoclax for CLL and SLL. https://www.fda.gov/drugs/resources information-approved-drugs/fda-approvesvenetoclax-cll-and-sll. Accessed 22 May 2019

16. US Food and Drug Administration. FDA approves venetoclax for CLL or SLL, with or without $17 \mathrm{p}$ deletion, after one prior therapy. https://www.fda.gov/drugs/informationondrugs/approveddrugs/ucm61030 8.htm. Accessed 15 October 2018.

17. Brown JR, O'Brien S, Kingsley CD, et al. Obinutuzumab plus fludarabine/ cyclophosphamide or bendamustine in the initial therapy of CLL patients: the phase 1b GALTON trial. Blood. 2015;125(18): 2779-2785.

18. Flinn IW, Panayiotidis P, Afanasyev B, et al A phase 2 , multicenter study investigating ofatumumab and bendamustine combination in patients with untreated or relapsed CLL. Am J Hematol. 2016;91(9):900-906.

19. Michallet A-S, Aktan M, Hiddemann W, et al. Rituximab plus bendamustine or chlorambucil for chronic lymphocytic leukemia: primary analysis of the randomized, open-label MABLE study Haematologica. 2018;103(4):698-706.

20. Stilgenbauer S, Leblond V, Foa $R$, et al Obinutuzumab plus bendamustine in previously untreated patients with CLL: a subgroup analysis of the GREEN study. Leukemia. 2018;32(8):1778-1786.

21. Souers AJ, Leverson JD, Boghaert ER, et al. ABT-199, a potent and selective BCL-2 inhibitor, achieves antitumor activity while sparing platelets. Nat Med. 2013;19(2):202208.

22. Gibson CJ and Davids MS. BCL-2 antagonism to target the intrinsic mitochondria pathway of apoptosis. Clin Cancer Res. 2015:21(22):5021-5029.

23. Hallek M, Cheson BD, Catovsky D, et al Guidelines for the diagnosis and treatment of chronic lymphocytic leukemia: a report from the International Workshop on Chronic Lymphocytic Leukemia updating the National Cancer Institute-Working Group 1996 guidelines. Blood. 2008; 111(12):5446-5456.

24. Common Terminology Criteria for Adverse Events (CTCAE) Version 4.0 https://www.eortc.be/services/doc/ctc/CT 
CAE 4.03_2010-06-14 QuickReference 5x7.pdf. Accessed 30 January 2019.

25. Howard SC, Jones DP, Pui CH. The tumor lysis syndrome. N Engl J Med. 2011; 364(19):1844-1854.

26. Rawstron AC, Villamor N, Ritgen M, et al. International standardized approach for flow cytometric residual disease monitoring in chronic lymphocytic leukaemia. Leukemia. 2007;21(5):956-964.

27. Kaplan EL, Meier P. Nonparametric estimation from incomplete observations. J Am Stat Assoc. 1958;53(282):457-481.

28. Seymour JF, Ma S, Brander DM, et al. Venetoclax plus rituximab in relapsed or refractory chronic lymphocytic leukaemia: a phase $1 \mathrm{~b}$ study. Lancet Oncol. 2017; 18(2):230-240.

29. LeBlond V, Aktan M, Ferra Coll CM, et al. Safety of obinutuzumab alone or combined with chemotherapy for previously untreated or relapsed/refractory chronic lymphocytic leukemia in the phase IIIb GREEN study. Haematologica. 2018;103(11):1889-1898.

30. Hiddemann W, Barbui AM, Canales MA, et al. Immunochemotherapy with obinutuzumab or rituximab for previously untreated follicular lymphoma in the GALLIUM Study: influence of chemotherapy on efficacy and safety. J Clin Oncol. 2018; 36(23):2395-2404.

31. Cramer P, von Tresckow J, Bahlo J, et al Bendamustine followed by obinutuzumab and venetoclax in chronic lymphocytic leukaemia (CLL2-BAG): primary endpoint analysis of a multicentre, open-label, phase 2 trial. Lancet Oncol. 2018;19(9):1215-1228.

32. de Vos S, Swinnen LJ, Wang D, et al. Venetoclax, bendamustine, and rituximab in patients with relapsed or refractory NHL: a phase Ib dose-finding study. Ann Oncol. 2018;29(9):1932-1938.

33.Zinzani PL, Flinn IW, Yuen SLS, et al Venetoclax-rituximab \pm bendamustine vs bendamustine-rituximab relapsed/refractory follicular lymphoma: CONTRALTO. Blood. 2020;136(23): 26282637.

34. Goede V, Fischer K, Busch R, et al. Obinutuzumab plus chlorambucil in patients with CLL and coexisting conditions. N Engl J Med. 2014;370(12):11011110.

35. Fischer K, Ritgen M, Al-Sawaf O, et al Quantitative analysis of minimal residual disease (MRD) shows high rates of undetectable MRD after fixed-duration chemotherapy-free treatment and serves as surrogate marker for progression-free survival: A prospective analysis of the randomized CLL14 trial. Blood. 2019; 134(suppl 1):36.

36. Hillmen P, Rawstron AC, Brock K, et al. Ibrutinib plus venetoclax in relapsed/refractory chronic lymphocytic leukemia: the CLARITY study. J Clin Oncol. 2019;37(30): 2722-2729.

37. Eichhorst B, Fink AM, Bahlo J, et al. First-line chemoimmunotherapy with bendamustine and rituximab versus fludarabine, cyclophosphamide, and rituximab in patients with advanced chronic lymphocytic leukaemia (CLL10): an international, openlabel, randomised, phase 3 , non-inferiority trial. Lancet Oncol. 2016;17(7):928-942. 